\title{
Tindak Tutur dalam Film Assalamualaikum Calon Imam
}

\author{
Sri Puji Astuti \\ Fakultas Ilmu Budaya, Universitas Diponegoro \\ sripujiastuti0116@gmail.com
}

\begin{abstract}
The purpose of this research is to describe the type and function of speech acts in the film of Asalamualaikum Calon Imamku. The method of data collection in this study is the observation method, continued by the note taking technique. Then, the data was analyzed by using the theory of speech acts. Based on the result of the research was found five kinds of speech acts used in the film of Asalamualaikum Calon Imamku, namely representative speech acts, directive speech acts, expressive speech acts, commissive speech acts, and declarative speech acts. Representative speech acts found function to report, expect, acknowledge, and show. Directive speech acts found function to force, advise, prohibit, ask, order, beg, invite, and suggest. Expressive speech acts found function to criticize, judge, blame, warn, and praise. The commissive speech act found function to promise and state the capability. The declarative speech act found function to authorize.
\end{abstract}

Keywords: Representative, expressive, directive, commissive, and declarative speech acts.

\section{Intisari}

Tujuan penelitian ini adalah mendeskripsikan jenis dan fungsi tindak tutur dalam film Asalamualaikum Calon Imamku. Metode pengumpulan data dalam penelitian ini adalah metode simak dengan teknik catat. Selanjutnya data dianalisis dengan menggunakan teori tindak tutur. Berdasarkan hasil penelitian ditemukan lima jenis tindak tutur yang digunakan dalam film Asalamualaikum Calon Imamku yaitu tindak tutur representatif, tindak tutur direktif, tindak tutur ekspresif, tindak tutur komisif, dan tindak tutur isbati. Tindak tutur representatif yang ditemukan berfungsi melaporkan, mengharapkan, mengakui, dan menunjukkan. Tindak tutur direktif yang ditemukan berfungsi memaksa, menasihati, melarang, meminta, menyuruh, memohon, mengajak, dan menyarankan. Tindak tutur ekspresif yang ditemukan berfungsi mengkritik, menilai, menyalahkan, memperingatkan, dan memuji. Tindak tutur komisif yang ditemukan berfungsi berjanji dan menyatakan kesanggupan. Tutur isbati yang ditemukan berfungsi mengesahkan.

Kata Kunci: Tindak tutur representatif, ekspresif, direktif, komisif, dan isbati.

\section{Pendahuluan}

Menurut Kamus besar Bahasa Indonesia film merupakan selaput tipis yang dibuat dari seluloid sebagai tempat gambar negatif yang akan dijadikan potret atau sebagai tempat gambar positif yang akan dimainkan dalam bioskop (2007:316). Definisi film tersebut berbeda dengan definisi film menurut Undang-Undang Republik Indonesia nomor 33 tahun 2009 tentang perfilman. Dalam Undang-Undang tersebut dijelaskan bahwa film 
merupakan karya seni budaya yang dibuat berdasarkan kaidah senematografi dengan atau tanpa suara dan dapat dipertunjukkan.

Persoalan yang diceritakan dalam film dapat bersumber dari persoalan yang dihadapi masyarakat, imajinasi , atau gabungan keduanya. Oleh karena itu, film juga dapat digunakan sebagai alat untuk menyampaikan pesan kepada masyarakat. Jadi, sebenarnya film merupakan sarana yang baik untuk menyampaikan pesan baik kepada pemirsa maupun masyarakat pada umumnya. Pesan yang disampaikan dalam film melalui percakapan antartokoh dengan menggunakan bahasa. Selain itu untuk menyampaikan pesan dalam film bukan sekadar penyampaian pesan melalui kata-kata melainkan selalu disertai dengan perilaku atau tindakan.

Film Assalamualaikum calon Imam berdasarkan jenisnya termasuk film cerita atau fiksi. Film ini merupakan alih wahana dari novel karya Ima Madania. Judul film dan judul novel sama yaitu Assalamualaikum calon Imam . Film Assalamualaikum calon Imam menceritakan seorang gadis bernama Nafisya Kaila Akbar (Fisya). Umi dan Abi Fisya bercerai karena Abi Fisya menikah lagi dengan Tante Mia. Tante Mia adalah adik ipar Abi Fisya. Karena paman Fisya meninggal, ia berwasiat agar Abi menikahi istrinya. Hal tersebut membuat Fisya sangat kecewa terhadap Abinya. Di samping itu, pada waktu itu Fisya menaruh hati pada Jidan. Jidan adalah teman bermain Fisya waktu kecil. Ternyata Jidan malah menikah dengan kakak Fisya yaitu Salsa. Hal tersebut membuat Fisya sangat kecewa karena Fisya sangat mencintai Jidan. Akhirnya Fisya bertemu dengan Alif, dosen dikampusnya. Fisya dan Alif akhirnya menikah di hadapan Abinya yang sedang sakit keras. Pernikahan tersebut terjadi di rumah sakit. Setelah mereka menikah Abi Fisya meninggal. Namun, tidak lama kemudian Fisya menderita penyakit multiple sclerosis. Penyakit tersebut dapat mengakibatkan kebutaan permanen dan kelumpuhan. Fisya tidak memberi tahu Alif tentang penyakit yang dideritanya. Fisya malah mempersiapkan perceraian dengan Alif. Akhirnya Ibu Fisya menceritakan penyakit Fisya kepada Alif dan Ibu Fisya mengharapkan mereka bersatu kembali.

Amanat yang ingin disampaikan dalam film Assalamualaikum Calon Imam yaitu seorang anak harus selalu menghormati orang tuanya bagaimanapun kondisinya. Percakapan atau dialog antarokoh dalan film ini sangat menarik karena banyak konflik yang dihadapi tokoh. Pertemuan antartokoh diduga menggunakan berbagai jenis tindak tutur dengan fungsi yang berbeda-beda. Berdasarkan latar belakang di atas dalam makalah 
ini dibahas jenis tidak tutur apa sajakah yang terdapat dalam film Assalamualaikum Calon Imam dan apa saja fungsinya.

Yule (1996:5-6) mendefinisikan pragmatik adalah studi tentang hubungan antara bentuk-bentuk linguistik dan pemakai bentuk linguistik itu. Lebih lanjut dijelaskan bahwa pragmatik juga melibatkan bagaimana orang saling memahami orang lain secara linguistik. Dalam pragmatik mewajibkan kita memahami orang lain dan memahami sesuatu yang mereka pikirkan. Menurut Mey (dalam Rahardi, 2009: 21) paragmatik adalah ilmu bahasa yang mengkaji penggunaan bahasa dengan mempertimbangkan konteks yang mewadahi. Sejalan dengan Mey, Rustono (2000:21) berpendapat bahwa pragmatik adalah cabang ilmu bahasa yang mengkaji bahasa dilihat dari aspek pemakaiannya. Jadi, dapat disimpulkan bahwa pragmatik mempelajari bahasa dengan memperhatikan konteks pemakaiannya.

Rahardi (2009:21) menjelaskan bahwa pragmatik bertugas mengkaji maksud penutur dalam penuturannya. Lebih lanjut dijelaskan bahwa analisis dalam pragmatik berpijak pada entitas konteks. Sedangkan yang dimaksud konteks adalah pengetahauan mengenai latar belakang yang sama-sama dimiliki oleh penutur dan mitra tutur yang menyertai serta mewadai pertuturan. Konteks ini sangat bermanfaat bagi penutur maupun mitra tutur untuk menafsirkan apa yang dituturkan.

Menurut Searle (dalam Rustono, 1999:39-43) tindak tutur dapat diklasifikasikan menjadi lima jenis yaitu tindak tutur representatif, direktif, ekspresif, komisif, dan isbati. Yang dimaksud tindak tutur representatatif adalah tindak tutur yang mengikat penuturnya terhadap kebenaran proposisi yang dituturkan. Tindak tutur representatif juga disebut dengan istilah tindak tutur asertif. Yang termasuk dalam tindak tutur representatif yaitu menyatakan, mengakui, melaporkan, memberikan kesaksian, menunjukkan, dan menyebutkan. Tindak tutur direktif disebut juga dengan istilah tintak tutur imposit. Tindak tutur direktif adalah tindak tutur yang dimaksudkan penuturnya agar mitra tutur melakukan tindakan sesuai dengan yang disebutkan dalam tuturan. Jadi, dalam tidak tutur direktif penutur mempengaruhi mitra tutur agar melakukan tindakan sesuai dengan yang dikehendaki penutur. Yang termasuk ke dalam tindak turur direktif yaitu tuturan memerintah, memberikan aba-aba, memaksa, mengajak, meminta, menyuruh, menagih, mendesak, memohon, menyarankan, dan menantang . Tindak tutur ekspresif yaitu tindak tutur yang dimakasudkan penuturnya supaya apa yang dituturkannya diartikan sebagai 
evaluasi terhadap hal yang disebutkan dalam tuturkan. Tuturan memuji, mengucapkan terima kasih, mengritik, mengeluh, menyalahkan, mengucapkan selamat, dan menyanjung merupakan tuturan ekspresif. Tindak tutur komisif adalah tindak tutur yang mengikat penuturnya agar melakukan hal atau memenuhi apa yang disebutkan dalam tuturannya, misalnya bersumpah, berjanji, mengancam, menyatakan kesanggupan, dan berkaul.Tindak tutur isbati adalah tindak tutur yang dimaksudkan penuturnya untuk menciptakan hal atau keadaan baru. Istilah tindak tutur deklarasi juga digunakan untuk menyebut tuturan isbti Yangtermasuk tuturan isbati misalnya melarang, mengizinkan, mengabulkan mengesahkan, memutuskan, mengangkat, membatalkan, dan memaafkan.

\section{Metode Penelitian}

Penelitian merupakan penelitian deskriptif kualitatif. Hal tersebut karena data-data dalam penelitian ini berupa tuturan tokoh dalam film Asalamalaikum Calon Imam. Sumber data penelitian ini adalah Film Asalamalaikum Calon Imam yang diperoleh dari laman www.youtube.com. Data dalam penelitian ini dikumpulkan dengan metode simak yaitu dengan cara menyimak dialog yang terdapat dalam film Asalamalaikum Calon Imam dengan teknik catat. Teknik ini digunakan untuk mencatat data yang telah diamati. Data dalam penelitian ini berupa penggalan-penggalan dialog yang mengandung tindak tutur dalam film Asalamalaikum Calon Imam . Data dipilih sesuai dengan kebutuhan penelitian. Dalam analisis data digunakan teori tindak tutur.

\section{Hasil dan Pembahasan}

Hasil penelitian menunjukkan bahwa ada lima jenis tindak tutur yang ditemukqn dalam film Assalamualaikum Calon Imam. Jenis tidak tutur yang ditemukan dalam film tersebut yaitu tindak tutur representatif, tindak tutur direktif, tidak tutur ekspresif, tintak tutur komisif, dan tindak tutur isbati.

\section{Tindak Tutur Representatif}

Tindak tutur representatif yang ditemukan dalam film Assalamualaikum Calon Imam dapat dilihat dalam coontoh berikut ini.

Dafa : "Dok gimana Dok?"

Dokter : "Saya sudah beri obat penurun tensi tapi HB-nya memang rendah hanya 4. Jadi, saya instruksi untuk tranfusi."

Tuturan di atas dituturkan oleh dokter yang memeriksa Profesor Husen (Abi) kepada keluarga Profesor Husen. Tindak tutur tersebut merupakan tindak tutur representatif 
berfungsi melaporkan. Dokter melaporkan kepada keluarga Prof Husen mengenai kondisi Prof Husen setelah diberi obat penurun tensi tapi HB-nya menjadi rendah. Karena kondisi tersebut, dokter memerintahkan untuk tranfusi darah. Tuturan dokter tersebut berarti perkembangan pasien kurang baik meskipun sudah diberi obat sehingga pasien perlu ditrasfusi.

\section{Dafa : "Fisya datang kan Umi? Sejak tadi Abi menanyain Fisya terus."}

Tuturan di atas dituturkan oleh Dafa, menantu Profesor Husen kepada Umi.Tuturan tersebut terjadi di luar kamar Profesor Husen dirawat. Profesor Husen selalu memanggil Fisya. Turutan tersebut termasuk tuturan representatif berfungsi mengharapkan. Pertanyaan Dafa yang ditujukan kepada Umi dalam tuturan Umi Fisya datang kan Umi? merupakan pertanyaan yang berisi harapan mengenai kedatangan Fisya. Pemakaian kan menunjukkan penutur mengharapkan mitra tutur menyetujui apa yang dituturkan. Hal tersebut juga diperjelas dengan pernyataan berikutnya yaitu sejak tadi Abi menanyain Fisya terus.

Fisya : "Kenapa saya Pak?”

Alif : "Setiap kali aku selesai salat istiharah yang muncul selalu wajah kamu. Kamu belum siap memberikan hati kamu padaku tapi aku siap memberikan hatiku padamu, itu pun kalau kamu bersedia.

Tuturan di atas terjadi setelah Abi memberitahu Fisya bahwa Alif melamar Fisya. Setelah mendengar berita tersebut Fisya bertanya kepada Alif. Tuturan Alif merupakan tindak tutur representatif berfungsi mengakui. Dalam tuturan tersebut Alif mengakui apa yang terjadi pada dirinya. Hal tersebut terdapat dalam tuturan setiap kali aku selesai salat istiharah yng muncul selalu wajah kamu. Kamu belum siap memberikan hati kamu padaku tapi aku siap memberikan hatiku padamu, itu pun kalau kamu bersedia. Pengakuan Alif tersebut menunjukkan bahwa untuk menentukan calon istri Alif tidak sembarang memilih tetapi dengan salat istiharah. Walaupun demikian, ia pun tidak memaksa Fisya menerimanya.

Umi : "Jodoh, hidup, mati itu takdir. Umi hanya bisa berdamai dengan takdir." Tuturan di atas merupakan tuturan Umi sebagai penutur dan Fisya sebagai mitra tutur. Tuturan tersebut terjadi karena sebelumnya Salsa dan Fisya sedang berdebat mengenai tanggapan Umi terhadap Tante Mia. Fisya memarahi Salsa hingga akhirnya Umi mengatakan bahwa jodoh, hidup, mati itu takdir. Umi hanya bisa berdamai dengan 
takdir.Tuturan tersebut merupakan tuturan representatif berfungsi menunjukkan. Maksud tuturan Umi adalah agar Fisya bisa menerima kondisi yang sedang dialaminya karena itu takdir.

\section{Tindak Tutur Direktif}

Berikut ini merupakan tindak tutur direktif yang ditemukan dalam film Assalamualaikum Calon Imam.

Alif : Pokoknya hari ini kamu jangan lupa ambil HP kamu banyak yang nelpon.” Tuturan di atas merupakan tuturan Alif sebagai penutur dan Fisaya sebagai mitra tutur. Tuturan Alif termasuk dalam tuturan representatif berfungsi memaksa. Hal tersebut juga ditandai dengan kata pokoknya.Tuturan tersebut dituturkan Alif karena HP Fisya terbawa Alif saat menolong anak kecelakaan di jalan. Pada saat HP Fisya dibawa Alif banyak yang menelpon Fisya. Oleh karena itu, Alif memaksa Fisya mengambil HP-nya.

Umi : “... Abi memang bukan suami Umi lagi. Tapi beliau tidak pernah berhenti jadi ayah kamu."

Turutan di atas dituturkan Umi kepada Fisya. Umi menjelaskan status Abi dengan tuturan Abi memang bukan suami Umi lagi. Tapi beliau tidak pernah berhenti jadi ayah kamu. Umi menuturkan kalimat tersebut untuk menasehati Fisya yang sedang marah dengan Abinya karena Abi menikah lagi dengan Tante Mia. Tuturan Umi tersebut juga menjelaskan kepada Fisya bahwa setelah Umi dan Abinya bercerai Abi tetap menjadi Abi Fisya. Jadi, dalam tuturan tersebut kalau suami istri sudah bercerai ada mantan istri atau mantan suami, tetapi tidak ada mantan anak. Oleh sebab itu, Umi mengharapkan agar Fisya sadar dapat menerima kehadiran Abi di hatinya.

Umi : "Abi, Abi jangan menyesal."

Tuturan di atas dituturkan Umi kepada Abi, mantan suami saat menjenguk mantan suami di rumah sakit. Mantan suami pada waktu itu sedang sakit keras dan menagis ketika melihat mantan istrinya datang. Oleh karena itu, mantan istri melarang mantan suaminya menyesali perbuatan yang telah dia lakukan karena menikah dengan wanita lain dengan menuturkan Abi, Abi jangan menyesal! Tuturan Umi termasuk dalam tindak tutur direktif melarang, Hal tersebut ditandaai dengan kata jangan.

Naila : "Maafin Abi ya Umi, maafin mama, maafin Naila juga Umi" Tuturan di atas dituturkan oleh Naila (anak Tante Mia) sebagai penutur dan Umi sebagai mitra tutur. Tuturan tersebut terjadi pada saat Naila menemui Umi yang baru datang di 
Makasar mau menjenguk Profesor Husen (mantan suami) . Tuturan Naila Maafin Abi ya Umi, maafin mama, maafin Naila juga Umi merupakan tindak tutur direktif berfungsi meminta. Naila memintakan maaf semua anggota keluarganya kepada Umi karena Naila menganggap keluarganya banyak melakukan kesalahan terhadap keluarga Umi.

Fisya : "Umi, Fisya mau ngobrol dulu sama Mas Alif sebentar. Boleh ya Umi?"

Tuturan di atas dituturkan Fisya sebagai penutur dan Umi sebagai mitra tutur. Pada saat itu Alif sedang duduk di ruang tamu. Umi menggandeng Fisya ke ruang tamu kemudian Fisya minta izin Umi kalau Fisya mau berbicara dengan Alif. Tuturan Fisya Umi, Fisya mau ngobrol dulu sama Mas Alif sebentar. Boleh ya Umi merupakan tindak tutur direktif berfungsi meminta. Pertanyaan boleh ya Umi menunjukkan bahwa penutur mengharapkan mitra tutur menyetujui permintaannya.

Suster : 'Pak."

Dafa : "Ya Sus"

Suster : "Pak ada keluarganya di depan."

Tuturan di atas terjadi di rumah sakit. Umi, Salsa, dan Jidan datang ke rumah sakit menjenguk Abi. Suster menemui keluarga Prof Husen yang ada di kamar untuk memberitahukan bahwa ada keluarga profesor Husen dengan mengatakan Pak ada keluarganya di depan. Tuturan suster merupakan tuturan direktif menyuruh tetapi tidak langsung. Dengan tuturan tersebut Suster bermaksud agar Dafa menemui keluarga yang baru datang.

Umi : "Fisya Abi kamu kan sudah datang jauh-jauh dari Makasar."

Fisya : "Ya kan buat pernikahannya Kak Salsa Umi."

Tuturan di atas terjadi di rumah keluarga Fisya. Abi datang karena Salsa mau menikah. Umi menemui Fisya di kamarnya. Kemudian Umi mengatakan Fisya Abi kamu kan sudah datang jauh-jauh dari Makasar.Tuturan tersebut merupakan tuturan direktif berfungsi menyuruh. Umi bermaksud menyuruh Fisya menemui Abinya akan tetapi Fisya menolak secara tidak langsung dengan tuturan Ya kan buat pernikahannya Kak Salsa Umi.

Alif : "Makan Yuk!

Fisya : "Nggak ah masih kenyang."

Tuturan di atas terjadi ketika Alif datang dari jalan-jalan pagi masuk rumah kemudian mengajak Fisya makan. Tuturan Makan yuk merupakan tindak tutur direktif berfungsi 
mengajak. Ajakan juga ditandai dengan kata $y u k$. Jadi, ajakan dalam tuturan tersebut merupakan ajakan langsung.

Alif : "Jadi, gini aku nanti sore kan mau berangkat ke Makasar. Aku jadi sekalian beli tiket untuk kamu.

Tuturan di atas terjadi saat Fisya sedang latihan taekwondo. Alif menemui Fisya di tempat latihan karena Fisya ditelepon Alif tidak diangkat. Alif memberitahukan bahwa ia akan berangkat ke Makasar. Alif juga sekalian membeli tiket untuk Fisya. Tuturan tersebut merupakan tindak tutur direktif berfungsi mengajak secara tidak langsung. Hal tersebut terdapat dalam kalimat Aku jadi sekalian beli tiket untuk kamu.

Abi : Fisya

Fisya : "Abi, Abi masih mau menjadi wali nikah Fisya?"

Tuturan di atas dituturkan oleh Fisya kepada Abinya di rumah sakit. Tuturan tersebut dituturkan Fisya karena sebelumnya Abi memberitahu Fisya bahwa Alif telah melamar Fisya. Melihat Abinya sakit keras Fisya berinisiatif menanyakan keinginan Abi untuk menjadi wali nikah Fisya. Pertanyaan Abi masih mau menjadi wali nikah Fisya?" merupakan tindak tutur direktif permohonan secara tidak langsung.

Umi : "Iya kan anak Abi ada dua Salsa sama kamu."

Fisya : "Umi, Fisya nggak bisa. Jangan paksa Fisya ya Umi."

Tuturan di atas terjadi di rumah keluarga Fisya. Abi datang karena Salsa mau menikah. Umi menemui Fisya di kamarnya. Umi bermaksud menyuruh Fisya menemui Abinya namun Fisya menolak dengan mengatakan Umi, Fisya nggak bisa. Jangan paksa Fisya ya Umi.Tuturan tersebut merupakan tuturan direktif berfungsi memohon. Fisya memohon kepada Umi agar tidak memaksa Fisya mememui Abi.

\section{Tindak Tutur Ekspresif}

Alif : "Kamu belum siap ya buka kerudung kamu di depan aku."

Tuturan di atas dituturkan Arif kepada Fisya. Meskipun mereka sudah menikah namun Fisya selalu memakai kerudung di depan suaminya, Alif. Oleh karena itu, Alif menanyakan kepada istrinya mengenai hal tersebut dengan tuturan kamu belum siap ya buka kerudung kamu di depan aku? Tuturan tersebut merupakan tindak tutur ekspresif mengkritik karena seharusnya Fisya tidak perlu memakai kerudung apabila bersama Alif di rumah karena mereka sudah resmi menjadi suami istri.

Fisya : "Pak saya tahu Bapak dekat dengan Prof Husen tapi saya enggak." 
Tuturan di atas merupakan tuturan antara Fisya sebagai penutur dan Alif sebagai mitra tutur. Tuturan Pak saya tahu Bapak dekat dengan Prof Husen tapi saya enggak termasuk jenis tindak tutur ekspresif berfungsi menilai. Dalam tuturan tersebut Fisya menilai bahwa hubungan Alif dengan Prof Husen (abinya) dekat. Sebaliknya Fisya menganggap hubungan dia dengan Abinya jauh. Tuturan tersebut merupakan ungkapan rasa kejengkalan Fisya terhadap Abinya.

Fisya : Aku hari ini mau masak tumis-tumisan, Mas Alif suka nggak?

Alif : 'Kamu masak apa pun yang kamu masak, aku suka."

Tuturan di atas terjadi ketika Fisya berada di dapur. Alif mendekat mau membantu tetapi Fisya menolak. Fisya memberitahu bahwa dia mau memasak tumis-tumisan. Fisya pun bertanya kepada Alif Mas Alif suka nggak? Tuturan Fisya dijawab Alif Kamu masak apa pun yang kamu masak aku suka. Tuturan tersebut merupakan tuturan ekspresif memuji karena hal tersebut berati Alif menyukai masakan istrinya. Dengan tuturan pujian tersebut diharapkan Fisya menjadi senang.

Alif : : "Aku sama sekali nggak nyangka kalau kamu nggak sayang sama bapak kamu sendiri. Aku nggak mau kamu menyesal Fisya.

Dalam tuturan di atas Alif sebagai penutur dan Fisya sebagai mitra utur.Tuturan Alif yang ditujukan kepada Fisya aku sama sekali nggak nyangka kalau kamu nggak sayang sama bapak kamu sendiri. Aku nggak mau kamu menyesal Fisya merupakan tindak tutur ekspresif berfungsi memperingatkan. Peringatan tersebut ditujukan kepada Fisya karena Alif telah mengetahui bahwa Fisya tidak menyayangi Abinya. Peringatan Alif tersebut diharapkan mampu mengubah sikap Fisya terhadap Abinya.

Teman Fisya : "Lu benci sama bokap lu seumur hidup lu karena bokap lu ngikutin wasiat adiknya. Sekarang lu malah ngikuti bokap lu.

Tuturan di atas terjadi ketika Fisya dan temannya sedang membaca informasi yang tertera di dinding kampus. Teman Fisya dengan tidak sengaja melihat cincin Fisya. Fisya menjelaskan bahwa ia sudah menikah dengan Alif. Pernikahan tersebut terjadi karena sebelumnya tanpa izin Fisya, Alif melamar Fisya. Teman Fisya mengetahui bahwa Fisya tidak menyayangi abinya karena Abi menikah dengan Tante Mia atas wasiat adiknya. Tuturan Lu benci sama bokap lu seumur hidup lu karena bokap lu ngikutin wasiat adiknya. Sekarang lu malah ngikuti bokap lu merupakan tindak tutur ekspresif berfungsi menyalahkan. Maksudnya teman Fisya menyalahkan Fisya karena ia menikah dengan Alif 
untuk menuruti Abinya. Jadi, tuturan teman Fisya bermaksud agar Fisya tidak mengulangi sesuatu yang tidak menyenangkan dalam hidupnya.

\section{Tindak Tutur Komisif}

Alif : "Aku tidak akan membiarkan kamu bersikap seperti anak kecil seperti itu. Tuturan di atas terjadi antara Alif sebagai penutur dan Fisya sebagai mitra tutur. Tuturan aku tidak akan membiarkan kamu bersikap seperti anak kecil seperti itu merupakan tindak tutur komisif berjanji. Tuturan tersebut dituturkan Alif setelah mengetetahui sikap Fisya terhadap Abinya. Maksud tuturan Alif yaitu Fisya harus menghormati abinya tidak boleh berpikiran seperti anak kecil.

Abi : "Kemarin itu Alif datang menemui Abi. Dia melamar kamu. Abi bilang ya terserah kamu. Kalau kamu senang Abi akan siap menjadi wali nikah kamu.

Tuturan di atas merupakan tuturan yang terjadi antara Abi sebagai penutur dan Fisya sebagai mitra tutur. Abi mengatakan kepada Fisya kemarin itu Alif datang menemui Abi. Dia melamar kamu. Abi bilang ya terserah kamu. Kalau kamu senang Abi akan siap menjadi wali nikah kamu. Tuturan tersebut merupakan tuturan komisif berjanji. Kata siap dalam tuturan tersebut berarti Abi Fisya menerima lamaran Alif sekaligus siap menjadi wali nikah Fisya.

\section{Tindak Tutur Isbati}

Tindak tutur isbati dalam film Asalamualaikun Calon Imam dapat dilihat dalam contoh berikut ini.

Fisya :" Bagamana Dokter?"

Dokter : “ Dari hasil pemeriksaan kami, Dik Fisya mengalami... Multiple sklerosis.

Tuturan di atas terjadi setelah Fisya diperiksa Dokter. Tuturan dokter dari hasil pemeriksaan kami, Dik Fisya mengalami... Multiple sklerosis merupakan tindak tutur isbati berfungsi memutuskan. Dokter memutuskan bahwa Fisya menderita Multiple sklerosis.

\section{Simpulan}

Hasil penelitian menunjukkan bahwa kelima jenis tindak tutur ditemukan dalam film Assalamualaikum Calon Imam. Kelima jenis tindak tutur tersebut adalah tindak tutur representatif, tindak tutur direktif, tindak tutur ekspresif, tindak tutur komisif, dan tindak tutur isbati. Tindak tutur representatif yang ditemukan berfungsi melaporkan, 
mengharapkan, mengakui, dan menunjukkan. Tindak tutur direktif yang ditemukan berfungsi memaksa, menasihati, melarang, meminta, menyuruh, memohon, mengajak, dan menyarankan. Tindak tutur ekspresif yang ditemukan berfungsi mengkritik, menilai, menyalahkan, memperingatkan, dan memuji. Tindak tutur komisif yang ditemukan berfungsi berjanji dan menyatakan kesanggupan. Tutur isbati yang ditemukan berfungsi memutuskan.

\section{Daftar Pustaka}

Pusat Bahasa dan Departemen Pendidikan Nasional. 2007. Kamus Besar Bahasa Indonesia. Edisi ketiga. Jakarta: Balai Bahasa

Rahardi, Kunjana. 2009.Sosiopagmatik kajian Imperatif dalam Wadah Konteks Sosiokultural dan Konteks Situasionalnya. Jakarta: Erlangga

Rustono. 1999. Pokok-Pokok Pragmatik. Semarang: CV IKIP Semarang Press.

------.2000.Implikatur Tuturan humor.Semarang: CV IKIP Semarang Press.

Undang-undang Republik Indonesia Nomor 33 tahun 2009 tentang Perfilman. http://www.kemenpar.go.id/userfiles/file/5168_1434-UU33Tahun2009Perfilman.pdf diunduh 18 Februari 2019.

Yule, George. 2006. Pragmatik . terjemahan Rombe Mustajab. Yogyakarta: Pustaka Pelajar. 